\title{
ATAQUES AO CORPO E TRAUMATOFILIA NA ADOLESCÊNCIA
}

Didier Drieu, Nadine Proia-Lelouey, Fabrice Zanello

\author{
Didier Drieu \\ Mestre conferencista \\ HdR em Psicologia \\ Clínica e \\ Patologia; CERReV, \\ Universidade de \\ Caen, França. \\ Psicoterapeuta \\ no Centro de \\ Orientação Acsea, \\ em Caen.
}

Nadine Proia-Lelouey
Professora de
Psicologia Clínica e
Patologia; CERReV,
Universidade de
Caen, França.
Psicoterapeuta
no Centro de
Orientação Acsea,
Caen.

Fabrice Zanello Psiquiatra infantil no Centro de Orientação Acsea, Caen.

\section{Tradução}

Pedro Henrique Bernardes Rondon

Psicanalista, membro efetivo da Sociedade de Psicanálise da Cidade do Rio de Janeiro (SPCRJ). Membro efetivo da Associação Brasileira para o Estudo da Psicologia Psicanalítica do Self (Abepps).
RESUMO: Discute-se a dimensão paradoxal e o sentido intersubjetivo dos comportamentos suicidas e de risco no adolescente. O corpo adolescente é, muitas vezes, objeto de sofrimento intenso. Trata-se de lutar contra tensões que se lhes colam à pele. Esses vividos estão ligados a múltiplas fontes traumáticas reveladas pela efração pubertária. Formula-se também a hipótese de que esses ataques corporais estejam ligados a mecanismos paradoxais, porque se são indicadores tanto de desafios pulsionais quanto da fragilização dos laços intersubjetivos, podem também revelar-se como sinal de reconstrução dos envoltórios, evidenciando trabalho de intersubjetividade em ação entre o adolescente e seus grupos de referência.

Palavras-chave: adolescência, ataques ao corpo, envoltório, traumatofilia.

ABSTRACT: Bodily attacks and adolescence traumatophilia.We wish to discuss the paradoxical dimension and the intersubjective sense of the suicidal and risky behaviors of adolescents. The adolescent body is often an object of intense sufering. It's about fighting the tensions that stick to their skin. Such experiences are linked to many traumatic sources revealed by pubertal breaking in. We also hypothesize that these bodily attacks are linked to paradoxical mechanisms, for if they are evidence both of drive challenges and of the enfeeblement of intersubjective bonds, they are likely to reveal themselves as a sign of reconstruction of the envelopes evidencing intersubjectivity at work between the adolescent and their reference groups.

Keywords: adolescence, bodily attacks, envelopes, traumatophilia. 
A partir de nosso interesse pelos comportamentos suicidas e de risco nas problemáticas de subjetivação dos adolescentes, desejamos discutir neste texto sua dimensão paradoxal e seu sentido intersubjetivo. Assim, esses comportamentos intervêm como verdadeiras violências autoinfligidas, sintomáticas de sofrimentos na dinâmica da apropriação subjetiva. É frequente que o corpo, para esses jovens, seja objeto de clivagem. As marcas da sexuação, na puberdade, se encontram desmentidas (ou são rejeitadas) pelo adolescente, se não tiverem sido previamente transformadas na relação primária com o objeto materno e, em seguida, nos laços com o ambiente. Trata-se, muitas vezes, de se despojar durante certo período das tensões que se lhes colam à pele, uma maneira de escapar à impotência a que se sentem entregues, às vezes por ataques diretos ao envoltório corporal, ou indiretos, ao se exporem a riscos. Esses vividos de passivação, revelados pela efração pubertária, estão ligados a múltiplas fontes traumáticas, mas muitas vezes são despertados por traumas primários ou por violências transgeracionais. Formulamos também a hipótese de que esses ataques corporais estão ligados a mecanismos paradoxais, tendo a ver com os desafios pulsionais (a integração do genital), mas também com sofrimentos na relação com o ambiente, impedindo a renovação das alianças intersubjetivas na adolescência. Esses comportamentos evidenciam, ao mesmo tempo, dificuldades para integrar a incerteza das vias da subjetivação, mas podem também se revelar como tentativas de mobilizar o ambiente, elos a um originário traumático por sua dimensão traumatofílica. Nesse contexto, sinais de sofrimento, esses ataques ao corpo podem também se transformar e se tornar sinais indicadores da reconstrução dos envoltórios, continentes mais simbólicos, evidenciando um trabalho de intersubjetividade em ação entre o adolescente e seus grupos de referência.

\section{OS ATAQUES AO CORPO NA ADOLESCÊNCIA: MANIFESTAÇÕES PARADOXAIS}

Há muito tempo as marcas corporais na adolescência têm sido reconhecidas como ritos de iniciação nas sociedades de cultura oral, se manifestando em especial no período de reclusão que precede as cerimônias de passagem, e por ocasião da saída desses períodos. No quadro da iniciação, estes são verdadeiros atos de submissão à lei do grupo, inscrições simbólicas que caracterizam a passagem da infância para a idade adulta. Trata-se, insistindo então, às vezes, do apagamento ou, ao contrário, do reaparecimento do corpo, ao marcar por meio de cerimônias a integração do sujeito jovem a seu grupo social. Hoje em dia essas marcas corporais na adolescência, sobretudo quando falamos das escarificações, das violências autoinfligidas, parecem ter perdido seu alcance simbólico. É muito frequente que sejamos levados a evocar a ideia de equivalentes, talvez mesmo de comportamentos suicidas que terminam por enraizar-se nos 
funcionamentos alexitímicos, em que a sensação toma a dianteira à dinâmica emocional, fantasmática. Se há muitas vezes uma "intimidade" com a morte nessas automutilações, o adolescente parece muito mais procurar projetar suas tensões em seu corpo para dominá-las melhor, o corpo se tornando objeto de perseguição com a puberdade.

Uma primeira análise desses comportamentos pode se apoiar na abordagem freudiana da pulsão. Ao introduzir o narcisismo e o "além do princípio de prazer", Freud reviu seu ponto de vista acerca do trauma, propondo a imagem do transbordamento da paraexcitação, e acerca da dinâmica pulsional, fazendo da desintricação pulsional a derradeira força da pulsão de morte. De maneira geral, as mudanças na puberdade são sentidas como traumáticas. E o serão ainda mais, uma vez que o jovem adolescente não pode apelar para os investimentos sublimatórios do trabalho de latência, nem para a confiabilidade dos objetos internos e externos. Como o equilíbrio de passividade/atividade se tornou precário, os mecanismos de projeção correm o risco de ser as únicas alternativas para tentar preservar uma aparência de domínio.

Também, nesse contexto, ante o medo do colapso, a menina púbere poderia se ver tentada a expulsar esse cheio demais de tensão sobre o corpo — odiado porque é objeto de transbordamento. Depois dos comportamentos de automutilação, por exemplo, a jovem tem a sensação transitória de recuperar o domínio sobre essa violência interna. Todavia, esse vivido é um engodo, porque a jovem púbere revive de forma contínua essas ameaças traumáticas, donde a impressão de se instalar de maneira duradoura numa vulnerabilidade narcísica quando, ademais, lhe falham os objetos internos e o apoio narcísico parental.

Assim funciona Nádia, ${ }^{1}$ de 14 anos e meio, que veio ver-nos em seguida a uma internação para iniciar um trabalho terapêutico. Trabalhamos então numa clínica integrada a um Centro MédicoPsicológico para adolescentes. Pudemos acompanhar Nádia em dois períodos distintos, interrompendo sua psicoterapia por ocasião de sua entrada no liceu. Quando a encontramos, ela havia ido diversas vezes ao pronto-socorro, porque costumava "se cortar" nos antebraços, alternando com comportamentos anoréxicos. Tudo vai mal desde que começou a sensação de que tem vergonha de seu corpo, isto é, a partir do momento que teve suas primeiras menstruações. Até então ela via a si mesma como protegida de sua mãe, num ambiente ao mesmo tempo preservado em relação ao exterior $e$, no entanto, lugar de tensões múltiplas, como pudemos ver mais tarde. A chegada da puberdade pareceu perturbar esse equilíbrio perfeito, deixando-a presa de dúvidas em relação a seus laços com os outros. Protegida de qualquer tensão até então, ela se sente de repente mal amada, traída pelas pessoas próximas, movimento que de início se rebateu sobre seu corpo. Este é objeto de investimento paradoxal: às vezes é idealizado, mas numa relação tão melancólica que

\footnotetext{
${ }^{1}$ Este exemplo é um relato de caso da clínica de Didier Drieu.
} 
depressa desperta rejeição e ódio. Aos nossos olhos, ela aparece como uma menina cuidada com rigor, em trajes fora de moda, como se tentasse manter uma ligação fetichista com a criança que pode ter sido. Durante muito tempo, não conseguindo tolerar a perda das ilusões, de seus objetos da infância investidos de maneira narcísica até então, ela afunda seu corpo numa espécie de 'rituais' pobremente erotizados. Aos poucos, numa forma de devaneio compartilhado conosco, essas cenas tomam 0 aspecto de roteiros marcados por uma alternância entre 'vazio' e 'cheio', provocando 0 risco de "desobjetalização" da pulsão (COURNUT, 1991; GREEN, 1995). Assim, esses ataques ao corpo aparecem como derradeira defesa contra o pavor do desligamento, do desinvestimento, 0 roteiro masoquista, protegendo-a do colapso melancólico. Outras figuras persecutórias aparecem. De saída, seu pai, glutão, que tem um prazer maligno de mastigar diante dela, conforme nos disse, e essa imagem deu início, nas nossas representações, a um roteiro de cena primária obscena. Em seguida, ficamos sabendo que pai e mãe se entendem quanto a tomar suas duas filhas, especialmente Nádia, como testemunhas de seus desacordos e da impossibilidade de sua separação.

O que poderemos dizer dessa configuração clínica? Diversos elementos se aliam aqui para tumultuar a adolescência de Nádia . Diante das mudanças que se operam em seu corpo na puberdade, a alternativa parece ser o roteiro masoquista. Ela se sente tentada a se cortar com regularidade, a ter uma atitude ascética em relação a sua alimentação para conservar o domínio da violência pulsional, de seus fantasmas. Estes, com sua força, reatualizam o traumático em curso, seja o "medo do colapso", seja vividos de domínio até então nunca pensados numa relação suficientemente boa com o materno (WINNICOTT, 1963). Assim, a excitação pulsional reativada por ocasião do choque da puberdade é sentida como perigosa - e isso por diversas razões. Ela desestabiliza o equilíbrio das defesas, tais como a clivagem e o desmentido, estabelecidas até então para se proteger do excesso traumático. Ela reativa o vivido de impotência percebido outrora ante a ausência de cuidados maternos de contenção e de um objeto paterno terceiro paraexcitante. As cenas de que, no início, somos a testemunha, vêm revelar sua impossibilidade de reverter o domínio vivido na interiorização dos laços.

De um lado, Nádia parece ter o dever de compor, desde a infância, com uma figura materna depressiva, um laço paradoxal que a leva a manter um 'espaço de punição' em comum com sua mãe (TERNYNCK, 2000). Esta, em vez de apoiar sua filha na construção da genitalidade (integração do feminino), contribui para repetir o 'traumático', deixando-a ouvir, nos momentos de discussão com seu marido, o quanto é preciso desconfiar dos homens, tão 'grosseiros' eles são, 'verdadeiros porcos'. Por outro lado, seu pai, personagem que ela apresenta como apagado há muito tempo diante da mulher, começa a se afirmar evocando com maior nitidez sua vida dupla. Há, de fato, por outro lado, uma ligação amorosa que ele vai terminar revelando à mãe de Nádia. Entretanto, na confusão, ele confidencia isso à filha, desvelando para ela em primeiro lugar seus sentimentos 
por outra mulher, a fim de que, dirá ele, 'ela proteja sua mãe das repercussões do golpe da futura separação deles'.

Assim, ao mal-estar da adolescente em sua dificuldade de integrar seu corpo sexuado, vem se associar uma problemática da relação: um distúrbio nas identificações com sua mãe, mas também das figuras de aliança pervertidas pelo projeto narcísico dos pais. Estes funcionam, de fato, na incestualidade, procurando manter, contra tudo e contra todos, sua relação de casal, mesmo que não se entendam mais, mesmo que tenham que sacrificar a individuação de suas filhas. Como no caso Dora, em que o roteiro histérico mascara as relações incestuosas na família, aqui as cenas masoquistas escondem uma configuração narcísica, “pré-edípica”, caracterizada por marcas traumáticas em grande escala na família (RACAMIER, 1992; DRIEU, 2006). Cada qual tenta por todos os meios preservar-se de qualquer movimento de perda. Para Nádia, essa cumplicidade se torna intolerável na adolescência, porque ela se encontra revelada de maneira súbita numa forma de "colapso traumático" no encontro abrupto entre seus fantasmas incestuosos ligados à puberdade, e a realidade incestuosa presente na família (JANIN, 1996).

Assim, no início do trabalho terapêutico, ela vive numa grande confusão tudo o que pode se aparentar às mudanças pubertárias: experiências de diferenciação em relação à intimidade da família, “cenas pubertárias” (GUTTON, 1991). Outros acontecimentos traumáticos vão começar a ser objeto de elaboração. Ela nos conta sua experiência, dois anos antes, de uma forma de iniciação sexual forçada (cena de apalpadelas) com um primo mais velho, odiando-se em demasia por se ter "metido na goela do lobo", como sua mãe veio a lhe dizer. Esta cena, como os repetidos ataques a seu corpo, nos parecem antes fazer parte das "tendências traumatofílicas", ou seja, de formas paradoxais de repetição do traumático (DRIEU, 2004). Por um lado, trata-se de dominar a excitação, e os atos podem tomar a dianteira sobre os fantasmas com a autodestruição, com o risco de que a autossensorialidade venha suprir os autoerotismos que lhe faltam. Por outro lado, Nádia parece procurar emergir de um "complexo traumático de filiação" dominado por uma cena primária violenta que a impede de se constituir em seu feminino (DRIEU, 2001; DRIEU et al., 2009).

Após um "primeiro tempo" de psicoterapia, ela voltou para um segundo período de trabalho mais analítico (dispositivo com divã/poltrona). Com 18 anos, terminando o curso do liceu, os pais separados, ela tenta aprender a coabitar com o namorado, sempre continuando a se ocupar com os problemas de alcoolismo de sua mãe. Embora tenham desaparecido em sua dimensão repetitiva, as automutilações permanecem sempre possíveis, como último recurso cada vez 
que ela se sente ameaçada de ser abandonada pelo namorado, ou quando está em violento desacordo com ele.

Numa atitude de emancipação, Nádia vem de novo nos ver, aconselhada pelo namorado e pela mãe deste. Ela arranjou outros confidentes. Diz que quer 'tentar domar o monstro que está sempre adormecido dentro dela'. Não suporta as cenas violentas que em várias ocasiões desencadeia contra sua vontade, a cada vez que o namorado vive a vida dele com os colegas, e fica imaginando que ele a trai. Sentindo-se dependente do outro, tendo medo da decepção, ela vive a si mesma então habitada pela paixão e ameaçada de se escarificar. Apesar disso, ela sente o namorado e os pais dele, com quem ela mora, como figuras consoladoras. ${ }^{2}$ O namorado, diz ela, sugere-lhe que tome certa distância de sua mãe que a puxa para dentro de seus próprios problemas. Esta, após um episódio de alcoolismo, decidiu por seu lado iniciar uma psicoterapia. Parece que diversos acontecimentos provocados pela adolescência de Nádia participam de uma possível diferenciação entre as protagonistas, além mesmo do trabalho terapêutico. Assim, ficamos sabendo que a avó materna, espécie de figura fetichizada, ao falecer, confidenciou aos filhos um segredo a propósito do comportamento vergonhoso de seu marido no tempo da guerra. Para Nádia, essas violências contribuem para o alcoolismo, até então mascarado, de sua mãe. Em consequência disso, ela começa a se interessar pela história da família, associando mais seus problemas às dificuldades familiares. Assim, relaciona a história vergonhosa do avô materno aos seus problemas. Ela imagina que seu avô, que denunciara pessoas da Resistência, era verdadeiro kapo ${ }^{3}$ que participara das violências infligidas aos prisioneiros nos trens da morte. Pouco a pouco, ela passa a ter pesadelos, e depois uma atividade onírica que nos sugeria que se operava um trabalho de construção/reconstrução das fronteiras, dos envoltórios do Eu.

Em Nádia as automutilações e o comportamento anoréxico vão desaparecer à medida que se constituem suas experiências adolescentes, ao mesmo tempo através de encontros com seus pares (a afiliação), e também na construção de um apoio narcísico parental (a transmissão). Quando voltamos a encontrá-la aos 18 anos, ela conseguira se apropriar mais daquilo que está se passando nela, mas também, e sobretudo, daquilo que a remete a um laço de dependência ao outro e aos outros. Assim, ela se autoriza a não dominar tudo o que empreende. Pôde aprender, então, por sua própria experiência, a suportar a incerteza que ainda a atormenta quando se vê "sozinha”, sem o namorado, ou "sozinha diante dos outros” (WINNICOTT, 1971). Entretanto, essa dinâmica só nos parece mobilizar-se após alguma forma de apoio narcísico parental. Primeiro, os laços com a família de seu namorado; depois, a redescoberta de sua própria família vão ajudá-la a abandonar o domínio no qual se encontra, a renovar formas de aliança mais

\footnotetext{
${ }^{2}$ A mãe do namorado, uma psicóloga, parece tomar Nádia sob sua proteção.

${ }^{3}$ Kapos eram membros da administração de campos de concentração que levavam as instruções de comandantes e guardas dos campos, e tinham autorização para chicotear prisioneiros por pequenas quebras de disciplina. (N. do T.)
} 
abertas em relação à sua geração, ao mundo da sociedade, permitindo-lhe levar em conta a incerteza em sua evolução psíquica. Se a integração do feminino continua sendo um processo interno da adolescência, esse, todavia, é objeto de uma “intersubjetivalização", uma vez que, como já vimos com Nádia, remete a uma dinâmica intersubjetiva (CAREL, 2006). Nesse contexto, as marcas do corpo (as automutilações, mas também em seguida os indicadores identitários estéticos, como um piercing) retomam seu lugar num processo de desenvolvimento, como vindo significar tentativas de reconstrução do espaço corporal e psíquico. Esses vividos se desenvolvem mais no grupo, o da família e o dos pares. Queremos mostrar isso por meio de nova vinheta clínica: algumas passagens de uma psicoterapia familiar que já descrevemos, em outro lugar, num artigo sobre os segredos de família (DRIEU et al., 2009).

\section{AS MARCAS DO CORPO E A RECONSTRUÇÃO DE UM ESPAÇO PSÍQUICO ALARGADO}

Trata-se de uma terapia de família que acompanhamos num CMPP em seguida ao acompanhamento terapêutico de dois dos filhos: psicoterapia individual para Paul, de 13 anos, quando voltamos a encontrá-lo com sua família, grupos psicoterapêuticos filhos/pais para Jean, dois anos mais novo. ${ }^{4}$ Os dois filhos têm tais dificuldades de comportamento que os colegas temem alguma forma de consolidação nos distúrbios borderline da adolescência. Marcados por problemas somáticos na infância (distúrbios do adormecimento, insônia, agitação para Paul; fechamento sobre si mesmo, ansiedade e recusa escolar para Jean), esses distúrbios do comportamento parecem ter-se apaziguado após a ajuda psicoterápica de que ambos se beneficiaram. Todavia, o mal-estar se reinstalou com força frente à aproximação da puberdade: agitação, acidentes em seguida a comportamentos de risco em Paul, fobia escolar e retraimento social em Jean. Ao fazer uma síntese, nosso colega, psicoterapeuta junto ao grupo de pais, evoca então as tensões que estão em jogo no casal parental. Ante a dimensão da escalada no sofrimento e a parada do grupo para Jean, fomos então levados a pensar uma orientação para uma psicoterapia de família — o que a família aceita em seu conjunto. Esta é um

\footnotetext{
${ }^{4}$ Trabalhamos como psicoterapeutas de família com abordagem analítica do grupo nesse CMPP. Ante os múltiplos problemas de determinadas famílias, e ligados a uma reflexão em torno do transgeracional, propomos encargos plurifocais a partir de um trabalho multidisciplinar e de nossa experiência com a psicanálise grupal. Trata-se de acomodar os diversos encaminhamentos terapêuticos para essas famílias, muitas vezes apanhadas nas armadilhas dos laços perversos, mas por outro lado na expectativa de um estado de devaneio [rêverie] frente à violência de seus traumas.
} 
pouco singular, uma vez que, ligada à nossa intenção de trabalhar em coterapia, vamos partilhar essa experiência com o antigo psicoterapeuta de Paul. ${ }^{5}$

Durante cerca de dois anos fomos literalmente apanhados no turbilhão maníaco de Paul. Assim, ele se alterna entre uma atividade sensório-motora exacerbada, pondo à prova a solidez de sua cadeira, manipulando objetos como um sucedâneo do jogo do carretel, e uma via fantasmática ramificada sobre a violência das origens. Nas sessões ele incessantemente questiona seu pai acerca da criação do mundo, dá evidência de fantasmas muito crus de eviscerações, de quedas no cosmo. Na vida, ele se 'quebra' em toda parte, após numerosos acidentes que parecem contaminar o resto da família: seu outro irmão Pierre Yves teve também um acidente de scooter. Se não ficamos surpreendidos de encontrar essa temática turbilhonante em Paul e, por extensão, na fratria, o desafio incessante entre o pai e o filho, bem como a escalada de autossabotagens que reina sobre o conjunto do grupo familiar, é que nos surpreendem mais. Esses acontecimentos, de feridas corporais nos filhos e os momentos de ausência de uns e outros, parecem algo como tempos de pontuação ante a aspiração no intemporal em que somos projetados, sobretudo com as histórias de Paul.

Como podemos compreender essas vivências corporais tão regredidas? As feridas fora da sessão e a atividade sensório-motora, os fantasmas dentro das sessões aparecem a princípio com o aspecto de verdadeiros ataques ao corpo, ao enquadre da psicoterapia da família. No entanto, é frequente que no a posteriori contribuam para mobilizar na nossa atividade contratransferencial um ajuste quanto à construção de uma grupalidade da família e, por conseguinte, de laços de aliança e espaços psíquicos para cada um. Esse período lembra os tempos de "agrupamento" nas psicoterapias de grupo em que os participantes, ante as angústias do agrupamento, com a aceleração na regressão que estas despertam, parecem se mobilizar nos “significantes formais, de demarcação” (ANZIEU, 1987; DRIEU \& PERSEHAYE, 2005). Trata-se então de sondar de maneira ativa a solidez do enquadre material antes de poder compartilhar suas sensações, de pôr à prova a confiabilidade do dispositivo e dos terapeutas. São, por conseguinte, verdadeiros "representantes arquiteturais", que põem à prova o enquadre material suscetível de mobilizar os limites do Eu, significantes formais evidenciando a construçãodesconstrução simultânea do espaço corporal e psíquico (HAAG, 1998).

Assim, em torno dos acidentes dos filhos, os pais começam a se mobilizar, evocando suas inquietações com alguma ambiguidade. Em seguida ao falecimento do avô materno, as associações explodiram

\footnotetext{
${ }^{5}$ Parece que fizemos essa opção sem saber grande coisa, no início, quanto à continuidade (do laço) e quanto a um casal "homossexuado", reforçando, por esse viés, o polo paterno e masculino que estava particularmente em sofrimento. Os filhos são quatro meninos, mas somente três deles vão acompanhar as sessões — o quarto viajou para estudar na ocasião em que iniciamos esse trabalho terapêutico.
} 
sobre os lugares de uns e de outros. O pai em especial evidenciou os desafios parricidas despercebidos que projetara sobre seu sogro ante o desprezo no qual se sentia colhido. 'Quanto a mim, eu tive quatro meninos e ele, coitado, só uma filha'. Testemunhas dessas 'competições narcísicas', nós nos vimos muitas vezes siderados e algumas vezes sugados num estado de intenso devaneio [rêverie] ante os jogos de palavras, a encenação que se instala no consultório.

Em seguida, as trocas interfantasmáticas entre pai e filho, depois entre os dois irmãos, Paul e Jean, nos pareceram evidenciar a passagem de um vivido sensorial a uma atividade mais simbólica. É claro que ficamos sempre colhidos em incessantes idas e vindas entre progressões e regressões. Paul parece aspirado pela violência das origens, interessando-se pelos buracos negros das galáxias, pelo desconhecido da pré-história. Ele evidencia isso com regularidade por meio de um imaginário desenfreado, ou algumas vezes mesmo por feridas corporais em seguida a acidentes ou a determinadas práticas de automutilação. Todos esses comportamentos nos parecem, no início, efeitos de um autoengendramento negativo, levando Paul, principalmente, a se instaurar como iniciador de sua própria violência, a recusar as origens, ao mesmo tempo que, de maneira paradoxal, as procura. Todavia, uma forma de partilha se instaura à volta de um questionamento sobre as figuras dos ancestrais. Cada qual consegue aos poucos começar a integrar a descontinuidade e o luto, de início por meio dos momentos de presença/ausência de uns e de outros nas sessões, e da repetição desses acontecimentos e partilha das emoções ante as perdas que começam a balizar o universo do grupo. Ficamos surpreendidos então de assistir a uma espécie de elaboração de um espaço fraterno que permite, primeiro, que pouco a pouco os filhos se afastem do centro dos laços de dependência a seus pais, que pensem na cumplicidade que já existe aí, mas é pouco elaborada entre os irmãos, e que, de fato, afasta os adultos e torna a instalar a diferença de gerações lá onde ela estava em suspenso.

Por ocasião de uma sessão agitada, o pai nos diz que está angustiado com as mudanças que se anunciam para seus filhos; fala de seus sentimentos muito contrastados para Paul, o que mais se parece com ele. Falamos então de um segredo de filiação na família paterna. Ficamos sabendo assim que a bisavó paterna fora excluída e banida do universo da família porque deixara seu marido para viver, na época, com artistas dos 'anos loucos'. A avó paterna teve que enfrentar uma sogra que a rejeitava, e contrair um casamento que a desvalorizava socialmente. Espécie de objeto predestinado, ela parece ter-se defendido do abandono e da vergonha, e ter reagido com seus filhos na alternância do excesso e do vazio. Diante das relações difíceis entre seus pais e com eles, este pai fala então sua adolescência tumultuada, levando-o a ser colocado num internato de padres jesuítas, e depois a cortar as ligações com sua família. A partir dessa sessão, dessas discussões com seu pai, Paul evoluiu bastante. Antes, ele inquietava os pais, provocando-os com seus investimentos negativos, sua paixão 
pelo mortífero. Ele pôde evocar com eles um prazer de investir determinadas aprendizagens. Absorvido pelas cenas pubertárias, ele começa a se distanciar nas sessões de terapia de família, evidenciando em atos seus desejos de mudança. No mesmo período, seu corpo se transforma: ele cresce, e se compraz de marcar essas transformações pela modificação de seu modo de se vestir, de sua apresentação. Muda sempre de penteado, experimenta tinturas, coloca um brinco na orelha. A partir dessas mudanças, Paul parece orquestrar uma espécie de dança corporal com seus dois outros irmãos, uns e outros se entregando a comparações, uma linguagem de corpo que passa da gestualidade para os jogos de sonoplastia, despertando como um eco todo um trabalho de interfantasmatização na fratria, nos pais e em nós mesmos.

Nós então nos empenhamos em perspectivas de mudança para a economia psíquica da família. De fato, assistimos de maneira contínua à integração da falta, da perda, nas conversas de uns e outros. Paul veio a expressar para nós, no a posteriori de uma ausência, que está apaixonado. Pierre Yves, apoiando-se em seu grupo de colegas, pôde investir num projeto de estudos que o leva cada vez mais a pensar numa separação de sua família. Apenas Jean parece resistir a essas mudanças, retomando por sua conta os fantasmas violentos de seu irmão contra sua escola, protegendo-se por trás de sua mãe, que não aguenta mais esse agarramento. ${ }^{6}$ Todavia, aos poucos, ele também consegue se projetar num futuro de colegial, diferenciando-se de seus irmãos, ao mesmo tempo que continua a reagir na paradoxalidade quando Paul e os pais falam em parar com a psicoterapia...

Para concluir, de forma ainda provisória, gostaríamos de retomar nossa interrogação inicial. Que ponto de vista metapsicológico podemos ter a propósito dessas violências autoinfligidas que são as automutilações — com maior frequência para os adolescentes — , os seus comportamentos extremos? Uma primeira ideia centrada numa compreensão mais econômica desses sintomas nos leva ao interesse pelas consequências da puberdade. Marcado pelo desligamento pulsional, o jovem recorria a formas de dívidas pagas com o corpo, ${ }^{7}$ para melhor resistir à violência do desequilíbrio passivo/ativo, correndo o risco de ser arrastado a uma forma de passivação; a outra potencialidade negativa estando na repetição, com sua vertente regressiva, a alexitimia. Todavia, esses ataques ao corpo remetem às dificuldades de apropriação subjetiva, de integração do feminino ou da

\footnotetext{
${ }^{6}$ Observemos de passagem que os pais tinham desejado ver nascer uma menina, na ocasião em que Jean veio ao mundo; que os prenomes dos filhos são todos portadores de um investimento grupal e institucional à imagem dos apóstolos ligados ao Filho de Deus e aos Papas, apesar de os pais, por outro lado, se declararem ateus.

${ }^{7}$ No original: contrainte par corps. No âmbito do Direito, essa expressão existe na língua francesa para designar uma condenação pronunciada pelas jurisdições repressivas, e consiste na obrigação de pagar uma dívida ao tesouro público. No passado, o sujeito ia para a prisão, donde a ideia de pagamento "com o corpo". (N. do T.)
} 
descontinuidade na construção do sujeito, e só podemos mesmo nos interrogar quanto a seu sentido tópico e dinâmico. Esses comportamentos sobrevêm com referência a violências nos apegos, a uma pregnância do traumático na relação objetal, o que remete a uma dinâmica de domínio no laço intersubjetivo. Sua paradoxalidade destaca a importância de conceber a subjetivação na adolescência como uma "intersubjetivalização". Ademais, intimado a abandonar o processo fálico, o adolescente se vê obrigado a integrar o feminino (ou a passividade). Essa apropriação subjetiva só pode ocorrer apoiada em múltiplas referências, sobre o objeto materno, é claro, mas também sobre os laços fraternos, sobre o grupo da família e os grupos de pares. Além disso, quando se pode encontrar o contexto intersubjetivo no qual nascem esses ataques ao corpo, como aqui por intermédio de uma psicoterapia de família, eles perdem sua dimensão de eterna replicação [mise en abîme ${ }^{8}$ ], à medida que se tornam portadores de significantes novos, na reconstrução de um espaço psíquico.

Se não é nova para nós, essa percepção dos distúrbios da adolescência e do cuidado nos parece, cada vez mais, ligada às mudanças antropológicas que estão modelando o trabalho de construção do sujeito adolescente. Os processos pubertários correm o risco de se tornarem uma forma de corpo a corpo num mundo paradoxalmente mais fechado à experimentação, à moratória psicossocial e, no final, ao derradeiro lugar de criação, ao desenvolvimento de seu psiquismo e de seus avatares.

Recebido em 2/6/2009. Aprovado em 25/9/2009.

\footnotetext{
${ }^{8}$ Mise en abîme é uma história dentro de outra história, se repetindo ao infinito, como as imagens de dois espelhos paralelos, colocados um diante do outro. (N. do T.)
} 


\section{REFERÊNCIAS}

ANZIEU, D. (1987) “Les signifiants formels et le Moi peau”, in et al. Les enveloppes psychiques. Paris: Dunod.

CAREL, A. (2006) "L'intersubjectalisation", in RICHARD, F.\& WAINRIB, S. (dir.). La subjectivation, Paris: Dunod (Coll. Inconscient et Culture).

CHAPELIER J.-B. (1998) “L'émergence des signifiants formels et leur transformation dans les groupes d'adolescents", in Les langages du groupe, Revue de Psychothérapie Psychanalytique de Groupe, Erès, n. 30:73-82.

COURNUT, J. (1991) L’ordinaire de la passion — névroses de trop, névroses de vide. Paris: PUF (Coll. Le Fil Rouge).

DRIEU, D. (2001) Traumatophilie à l'adolescence et enjeux thérapeutiques. Thèse de doctorat. Université Denis Diderot, Paris VII.

(2004) Les empreintes traumatiques en jeu dans les tentatives de suicide à l'adolescence. Perspectives Psychiatriques, 43, 2:130-136. (2004b) Automutilations, traumatophilie et enjeux transgénérationnels à l'adolescence. Adolescence, 22, 2:311-323.

(2006) Dispositif psychothérapeutique face à la paradoxalité en famille. Dialogue, 172:37-52.

\& HARDOUIN, F. (2008) Le fraternel en souffrance: sa place dans le travail psychothérapeutique familial. Dialogue, 179:33-44.

\& PERSEHAYE, C. (2005) Passage de la destructivité à la pensée dans les groupes de psychodrame à l'adolescence. Revue de Psychothérapie Psychanalytique de Groupe, n.44:173-184.

, ZANELLO, F. \& PROÏA-LELOUEY, N. (2009) Secrets de famille, auto-engendrement négatif et enjeux thérapeutiques. Cahiers de Psychologie Clinique, Bruxelles: De Boeck université:121-138.

GREEN, A. (1982/1993) Narcissisme de vie, narcissisme de mort, Paris: Minuit. (1988) La pulsion et l'objet. Propédeutique, la métapsychologie révisée.

Paris: PUF/Champ Vallon, 1995:13-32.

GUTTON, P. (1991) Le pubertaire. Paris: PUF. (Coll. Le Fil Rouge).

HAAG, G. (1998) Travail avec les représentants spatiaux et architecturaux dans les groupes de jeunes enfants autistes et psychotiques, Les langages du groupe, Revue de Psychothérapie Psychanalytique de Groupe, Erès, n. $30: 47-62$.

JANIN, C. (1996) Figures et destins du traumatisme. Paris: PUF (Coll. Le fait psychanalytique).

RACAMIER, P.-C. (1992) Le génie des origines — psychanalyse et psychoses. Paris: Payot.

WINNICOTT, D.-W. (1963/2000.) “La crainte de l'effondrement”, in La crainte de l'effondrement et autres situations cliniques, tr. fr. Paris: Gallimard, NRF.

(1971) Jeu et réalité, NRF, Gallimard, 1975.

Didier Drieu

drieu.didier@neuf.fr 